\title{
"El vent lluita per ésser flor". \\ La idea de la metamorfosi \\ en la poesia de Joan Brossa i Federico García Lorca
}

\author{
"El vent lluita per ésser flor". \\ The idea of metamorphosis \\ in the poetry of Joan Brossa and Federico García Lorca
}

\author{
Marcin Kurek \\ Uniwersytet Wrocławski \\ marcin.kurek@uwr.edu.pl \\ Justyna Ziarkowska \\ Uniwersytet Wrocławski \\ justyna.ziarkowska@uwr.edu.pl
}

\begin{abstract}
In the studies on poetry by Joan Brossa, his literary inspirations from the French tradition are indicated, but his connection with Spanish-language literature is almost nonexistent. The purpose of this article is to present Brossa's testimonies about his Federico García Lorca readings and to compare his "Sonet del pur estrèpit" (1949) with Lorca's "Muerte" (1931). Both poems show textual and conceptual similarities and share the theme of metamorphosis, so we propose their analysis to look for possible inspirations in different philosophical and aesthetic traditions (surrealism, Ovid, Darwin, Zen Buddhism).
\end{abstract}

Keywords: Joan Brossa, Federico García Lorca, metamorphosis 


\section{LORCA/BROSSA: RELACIONS I AFINITATS}

L'anàlisi de dos poemes relativament breus, "Muerte" de Federico García Lorca $i$ "Sonet del pur estrèpit" de Joan Brossa, que ens proposem en el present text parteix del nostre interès per estudiar la xarxa de relacions i interferències estètiques, ètiques i textuals que abunden en l'obra del poeta, dramaturg i artista barceloní. No pretenem que les convergències entre els dos autors siguin efecte d'una influència directa de Lorca sobre Brossa -el fenomen invers és impossible per motius cronològics-. Com ja ha estat assenyalat en un estudi dedicat a les seves obres teatrals, les semblances temàtiques o estructurals es poden entendre com a fruit d'unes fonts comunes d'inspiració o com a respostes paral·leles als reptes i les preguntes de l'època (vegeu Kurek \& Ziarkowska, 2014). No obstant això, en el cas dels dos poemes analitzats, les similituds estructurals $i$ textuals però sobretot conceptuals i filosòfiques justifiquen la hipòtesi d'una correspondència clara i potser deliberada.

Els vincles que permeten confrontar l'emblemàtic representant de la Generació del $27 \mathrm{amb}$ un dels personatges més originals de la neoavantguarda catalana no són del tot evidents. Joan Brossa, en el seu fort compromís a favor del catalanisme cultural i polític, des dels seus primers textos que recordaven la seva experiència bèl-lica i els primers poemes, va apostar per escriure en català, aprofundint, d'una banda, en el llenguatge parlat a casa i al carrer i, de l'altra, en la tradició literària desenvolupada en la seva llengua materna. A més, si considerem la seva condició d'avantguardista declarat, el caràcter sincrètic de la seva enorme obra, la seva estreta amistat amb pintors Joan Miró, Antoni Tàpies, Joan Ponç-i les crítiques formulades contra el mainstream literari català, no ha d'estranyar la complexitat de la seva relació amb altres escriptors. El 1990, en una de les poques entrevistes realitzades en castellà, declarava:

Con los literatos, en general, no me entiendo. Hablamos el mismo lenguaje, pero es distinto, siempre hay un recelo. La literatura catalana actual me interesa en ciertas cosas, pero el tono blando oficial no me va. Sí, tengo más amigos entre los pintores. Con un pintor inteligente conecto muy bien. Sintonizamos ondas parecidas. (Alegre Heitzmann, 19901991, p. 13)

La seva postura de certa desconfiança respecte al propi medi literari l'ha acompanyat també en l'època més primerenca, com mostra una confessió seva de 1971, feta a Jordi Coca:

Sempre m'ha mogut a expressar-me un embat de dins a fora i, d'acord amb la meva conformació, fins i tot amb les meves condicions fisiològiques, va prevaler la literatura, que no és pas un mitjà que m'agradi gaire; potser el trobo massa indirecte. (1992, p. 19)

Deixant de banda aquestes objeccions, sovint, quan li preguntaven pels seus models literaris o estètics, Brossa esmentava els més antics, com els medievals Ausiàs 
March o Guillem de Cabestany, o els representants de la generació anterior (J. V. Foix, Sebastià Gasch, Joan Salvat-Papasseit), o fundadors del moviment ADLAN (Joan Prats), tots ells nascuts en la dècada de 1890, als quals la crítica ha sumat alguns clàssics catalans del segle XIX, com Jacint Verdaguer o Miquel Costa i Llobera, inspiradors d'algunes de les seves obres (Bordons, 1988, p. 33). Entre els escriptors o pensadors estrangers que declarava haver llegit en diferents moments de la seva trajectòria destaquen Nietzsche, Rimbaud, Mallarmé, Whitman o Blake, però significativament molt poques vegades són autors en llengua castellana. Interrogat directament per aquesta qüestió, esmenta Pablo Neruda i César Vallejo, dos poetes hispanoamericans, després Miguel Hernández i Ramón Gómez de la Serna, per revelar finalment el paper que exerceix entre ells el poeta granadí:

En primer lugar García Lorca. Iba siempre con un libro de Lorca en el bolsillo. Una edición popular del Romancero gitano que se publicó cuando lo asesinaron, tenía un prólogo de Alberti y dibujos de José Caballero. [...] Y a Lorca siempre lo pongo como ejemplo de poeta político, auténtico, sin dimitir de la imaginación; Poeta en Nueva York, es un libro bello y muy "social”. (Alegre Heitzmann, 1990-1991, p. 12)

Pocs mesos abans de la mort de Brossa, una exposició de les seves obres va llançar certa llum sobre la relació que l'unia amb l'autor de Bodas de sangre. Al juny de 1998, en commemoració del centenari del naixement de Lorca, la madrilenya Residencia de Estudiantes va inaugurar la mostra de 47 objectes titulada "Brossa piensa en Federico", que un mes més tard va ser traslladada a la casa-museu Huerta de San Vicente a Granada. Arran d'això el poeta barceloní va fer una sèrie de comentaris sobre l'obra lorquiana, entre altres, sobre el concepte de duende: "Federico tenía el duende más grande. [...] La gente quiere cosas amables, luz del sol. El duende siempre impresiona porque forma parte de lo críptico, de lo misterioso. ¡Y a mí que me parece que eso es precisamente el arte!" (Mora, 1998). També suggerí un curiós vincle entre l'exemplar de Romancero gitano que portava durant la guerra i una vivència dramàtica:

Me lo llevé al frente del Segre, a la guerra. Siempre en el bolsillo. Un día, en la trinchera, oí una voz: "Juan". Salí de allí, y un minuto después cayó un mortero. Luego supe que nadie me había llamado. Un misterio, ¿no? (Mora, 1998)

El que Brossa va exaltar en l'obra lorquiana era la seva alegria, saviesa i forma de tornar a allò essencial: "Solo los más grandes encuentran las raíces del universo sin moverse de la tierra que pisan" (Mora, 1998). Així mateix declarà que la frase lorquiana que més s'estimava pertanyia al poema "1910 (Intermedio)", de Poeta en Nueva York: "No preguntarme nada. He visto que las cosas / cuando buscan su curso encuentran su vacío" (García Lorca, 1997a, p. 512). Com a part de la seva participació en la celebració del centenari, Brossa va anunciar un poema visual en homenatge directe a Lorca que havia de tenir lloc als jardins de la Residencia i que no arribà a materia- 
litzar-se. La idea va consistir a gravar els mots "A Federico" en un arbre i escampar les lletres de l'alfabet per terra. També va esmentar la idea d'una psicofonia, a manera de veu electrònica: "Un agujero en la tierra: $y$ cuando te acercas una voz oscura recita sus poemas. Pero no sé si podré" (Mora, 1998). Com a prova de la important presència lorquiana en les lectures de Brossa, podem considerar també un dels seus poemes tardans que va citar en l'obertura de l'esmentada exposició:

Líric

Ha estat descobert que la poesia és un medicament calmant $\mathrm{i}$ antidepressiu que actua sobre el metabolisme del sistema nerviós central...

Jo faria un tractament amb poemes

de Federico Garcia Lorca

i Joan Salvat-Papasseit. (Brossa, 1997, p. 69)

Durant una taula rodona organitzada en el moment de cloenda de l'exposició a Huerta de San Vicente, Brossa va posar un punt final a la seva història lorquiana dient:

De niño, en el colegio me habían enseñado toda la mala poesía del mundo. Cuando lo leí, descubrí que aquello era buena poesía, verdadera poesía. Lorca conmocionó mi propia poesía, mi vida... Alguien me alentó a que hiciera algo sobre Federico con motivo de su centenario. Descubrí entonces que durante años había hecho poemas visuales y cosas inspiradas en Lorca, trabajos que no se habían presentado nunca y en los que Federico yacía subconscientemente. (Abril, 1998)

Els testimonis citats mostren que, entre els pocs autors de llengua castellana a què Brossa va llegir amb admiració, Federico García Lorca ocupava un lloc privilegiat. Llegí els seus poemes sent un adolescent de disset anys, el van acompanyar en un moment crític des de la perspectiva existencial (la guerra i la ferida) i, pocs mesos abans de la seva mort, Brossa recordava el poeta granadí com a remei calmant i antidepressiu, rendint-li un homenatge mitjançant un poema literari i un altre projecte de poema visual.

\section{LA METAMORFOSI EN LORCA}

El tema de la metamorfosi en l'obra de Federico García Lorca és bastant freqüent $i$ ha estat expressat tant en el seu teatre com en la poesia i el dibuix. Pel que fa al teatre, cal remarcar especialment El Público, on, en el quadre segon ("Ruina romana"), es troba el conegut diàleg en què la Figura de cascavells li proposa can- 
vis a la Figura de pàmpols (“ ¿Si yo me convirtiera en nube? / Yo me convertiría en ojo" [García Lorca, 1997b, p. 285]) que continuen fins a la persecució, la violència i el sadisme, i queden bruscament acabats per la rotunda constatació de l'Emperador quan diu "Uno es uno y siempre uno" (García Lorca, 1997b, p. 293). Pel que fa a la poesia, aquest motiu sembla molt més freqüent: apareix en el Romancero gitano (per exemple la coneguda frase "Pero yo ya no soy yo, / ni mi casa es ya mi casa" [García Lorca, 1997b, p. 421] del "Romance sonámbulo"), en el Poema de cante jondo, en Canciones, però Lorca li dedica una especial atenció en el seu llibre de tall surrealista Poeta en Nueva York. Aquí, per exemple al poema "Iglesia abandonada", el subjecte líric plora pel seu fill, que no tindrà; després el fill es transforma en una nena, un peix i el mar. Els protagonistes del poema "Panorama ciego de Nueva York" també estan sotmesos a un procés de transformacions inesperades: "Pero no, no son los pájaros, / porque los pájaros están a punto de ser bueyes. / Pueden ser rocas blancas con la ayuda de la luna, / y son siempre muchachas heridas / antes de que los jueces levanten la tela" (García Lorca, 2015, p. 207). En el poema "Cementerio judío" llegim que: "Y el agua era una paloma / Y la madera era una garza, / Y el plomo era un colibrí" (García Lorca, 2015, p. 254). Al llarg de tot el poemari també els espais canvien contínuament. Així, en el poema “Nueva York. Oficina y denuncia” llegim: „No es el infierno. Es la calle / No es la muerte. Es la tienda de frutas" (García Lorca, 2015, p. 252) i fins i tot el rostre del subjecte líric és "distinto cada día", en "Vuelta de paseo" (García Lorca, 2015, p. 165).

El tema de la metamorfosi va ser àmpliament utilitzat en la literatura surrealista. La poesia de signe bretonià va establir una relació amb el primer vers del cant quart d'Els cants de Maldoror lautréamontians que deia: "C'est un homme ou une pierre ou un arbre qui va commencer le quatrième chant" (Lautréamont, 2016, p. 121). Els surrealistes ho van entendre com una imitació literària del procés que s'efectuava en la subconsciència o en el somni quan una forma es transformava en una altra amb gran facilitat. La metamorfosi dels personatges o de les coses es tornà així un mètode d'introducció dels somnis en l'àmbit de la consciència i subratllava a més la convicció que no existien paraules, objectes o persones inequívoques. La presència de les metamorfosis i la revelació de totes les fases del procés transformador va ser efecte de la diagnosi surrealista de la realitat (el reconeixement de la fragilitat de les fronteres entre diferents formes d'existència i el qüestionament de la naturalesa monològica del món), però alhora fou una manera de transformar el món.

Els surrealistes van aprofundir la idea de la desintegració del subjecte, d'una ban$\mathrm{da}$, en una forma social condicionada per la moral dominant $\mathrm{i}$, de l'altra, una forma autèntica, capaç d'expressar els seus propis desitjos. Per aquesta raó s'utilitzava freqüentment el motiu del doble en El perro andaluz, en diversos quadres de Dalí com Autoretrat desplegant-se en tres o Natura morta al clar de lluna, en la prosa poètica de Lorca, com ara "Santa Lucía y San Lázaro", o en la seva obra teatral Así que pasen cinco años o en El Público. El procés transformador descrit per Lorca en el seu poe- 
mari novaiorquès presenta uns protagonistes poètics que s'adonen de la seva alteritat i del fet que es troben en un lloc equivocat. Lorca, i més tard Brossa, miren així de democratitzar el recurs de l'hamartia-com diria Leszek Koczanowicz (2020, p. 44)-, ja que la modernitat fa que el sentiment de desdoblament de l'individu que se separa de si mateix i desitja tornar al seu propi "jo" sigui general i universal. Com indica igualment Koczanowicz (2018, p. 349), el desdoblament en un "jo" i un "jo-com-algú-diferent", vist com un tret integral de la naturalesa humana, està present especialment en la psicoanàlisi, que intenta forçar el discurs de la inconsciència a manifestar-se en la consciència i estrènyer les relacions entre dues persones de les quals una escolta el llenguatge de l'altra. Dit d'una altra manera: la psicoanàlisi permet entendre i acceptar el fenomen de la desintegració del subjecte.

Tant el recurs de l'hamartia com el motiu de la metamorfosi provenen, òbviament, de l'antiguitat. En la mitologia antiga les metamorfosis consistien en la degradació d'una persona en animal de vegades per un temps determinat, de vegades definitivament. Sempre, però, l'ésser transformat -ho subratlla José Ramón del Canto Nieto (2007, p. 24)- seguia essent d'alguna manera el mateix que abans de la metamorfosi, conservava alguns trets del seu caràcter anterior, el llenguatge o la seva ment humana. Així que la metamorfosi feia que un ésser transformat fos un mateix i un altre simultàniament. La metamorfosi unia també a manera de llindar un abans i un després. La metamorfosi formava monstres, éssers híbrids, situats en la frontera entre dos mons. En el poema "Muerte" de Lorca tota la cadena de transformacions també demostra que el seu efecte no és un canvi radical i que, després de l'esforç, la naturalesa de les coses segueix persistint.

Les metamorfosis clàssiques investigaven a més les causes de la transformació d'un home en animal. Lorca, igual que la resta de poetes avantguardistes fascinats per aquest fenomen, no busca tal explicació. Les seves transformacions són igualitàries i més aviat horitzontals, espontànies i atzaroses: no contemplen la possible degradació d'un ésser espiritual en un ésser natural. Sembla que més que el procés de metamorfosi en un ésser diferent, al poeta li interessa l'extensió del mateix ésser, l'ampliació de l'existència en una pluralitat de formes.

El poema "Muerte", de Federico García Lorca, va ser inclòs en el llibre Poeta en Nova York, efecte del seu viatge americà, als Estats Units i Cuba, realitzat entre 1929 i 1930. El manuscrit no té data, però el text fou publicat a Revista de Occidente el 1931. El poema obre una secció del llibre dedicada a la mort i titulada "Introducción a la muerte. Poemas de la soledad en Vermont" que, en la versió editada per Andrew A. Anderson, abasta 11 poemes que constitueixen una pausa en el vagareig urbà i una fugida dels paisatges metropolitans. Relaten la mort per càncer d'un nen de deu anys i la d'una nena ofegada en un pou: busquen, comptat i debatut, noves formes d'expressió per a la mort.

El poema que ens interessa es divideix en tres parts. En la primera observem quatre animals que s'esforcen per perdre la seva identitat: el cavall, que simbolitza la 
llibertat, vol transformar-se en gos, un ésser terrestre, símbol de la domesticació, però el gos vol esdevenir oreneta, missatgera voladora de la primavera, mentre que l'oreneta vol ser abella, un subjecte també aeri, però treballador i esclau. El cicle el tanca l'abella, que vol ser cavall. Aquests protagonistes volen adoptar una altra identitat de la que tenen, volen superar la seva condició. No obstant això, el cavall, tal com hem observat en els mites antics, després de tota una sèrie de metamorfosis, segueix essent cavall. La seva recerca d'una identitat diferent en altres éssers li ha fet la vida, però no ha transformat la seva forma. Val la pena subratllar també "l'esforç" que suposa la metamorfosi en Lorca i la "lluita" que portarà també el procés transformador en Brossa: tots dos recorden el dolor amb què es relaciona el canvi sofert per Gregor Samsa en l'obra de Kafka. És un canvi que implica lluita i que ve acompanyat d'un dolor que s'assembla al del part.

En la següent part del poema veiem diverses formes naturals fugint de la mort (la rosa que lliga llums i xiscles en sucre, el sucre que somia amb el punyal, el punyal que cerca la lluna, la pell i els nus). Lorca s'estima molt les formes, viure és un continu despullar-se de formes obsoletes a la recerca de noves formes. Les transformacions són una manera d'evitar la mort. És també objectiu de tota metamorfosi des dels seus orígens clàssics. El contrari d'una forma no és la seva versió transformada sinó la seva desaparició, el buit. Els morts que ja no tenen forma i deambulen com buits apareixen freqüentment en les pàgines del poemari lorquià. La mort a Poeta en Nova York -tal com la interpreta Manuel Fuentes Vázquez (1992-1993)- no és una necessitat, sinó una manera de desaparició de la forma. El poema "1910 (Interludi)", citat per Brossa, també acaba evocant la imatge esfereïdora del buit: "Hay un dolor de huecos por el aire sin gente / y en mis ojos criaturas vestidas ¡sin desnudo!" (García Lorca, 1997a, p. 512).

Les cadenes de les transformacions juxtaposades a manera d'enumeracions equívoques (un altre tret que uneix Brossa amb Lorca) organitzen l'estructura del temps de manera semblant a les estructures heterocròniques (unes variants de les heterotopies relatives al temps) proposades per Michel Foucault (1999, p. 433). El fet que es donin constitueix un "error de temps" en el qual es juxtaposen lapses aparentment desplaçats i incompatibles. El fet de passar d'una forma a una altra eludint la mort trenca la tradicional linealitat del temps. Les següents metamorfosis del poema neutralitzen o reverteixen el joc de relacions en què es reflecteixen o es mostren. Lorca proposa que no ens defensem en l'escassetat del temps, sinó que vencem la temporalitat a través d'un flux discontinu immanent que no es refereixi a cap instància externa. En l'última part del poema tornem al mateix cicle tancat de transformacions que ja coneixíem de l'inici. El jo poètic diu que busca "un serafín de llamas" i simultàniament l'és. En l'última frase, la mort, que és alhora gran, diminuta i invisible, interromp aquest cicle de transformacions i ho fa "sense esforç". No hi ha naturalesa estable i sense canvis. Estable és la mort. Una mort despullada de la forma permet que les metamorfosis cronològiques, espacials o figuratives es realitzin sense esforç. 


\section{LA METAMORFOSI EN BROSSA}

El concepte de metamorfosi o transformació està present en l'obra brossiana en totes les seves dimensions. A les primeries del segle XX un dels seus artistes preferits del món de les arts escèniques populars era Leopoldo Fregoli, actor i transformista italià, autor d'espectacles en els quals es canviava de roba a una velocitat vertiginosa, transformant-se durant l'espectacle en desenes de personatges de diferents sexes i edats. Una frase atribuïda a Fregoli va arribar a ser el lema que patrocinava tota la seva trajectòria:

he vist que el seu art encaixa en la meva manera d'entendre la poesia, i això resumit en aquella frase seva que sembla d'Heràclit: "L'art és vida i la vida és transformació". Exacte! És el meu lema de poeta. Quina força de creació no té la metamorfosi! (Coca, 1992, p. 28)

La transformació com a mecanisme vital, tant en el seu aspecte existencial com artístic, l'ha acompanyat al llarg de tota la seva trajectòria, fent-li prendre, abandonar i reprendre diverses formes, gèneres i estils en la poesia literària (el sonet, l'oda, la sextina, el poema sintètic, els poemes basats en la cita, etc.), en el teatre (les accions-espectacle, els monòlegs de transformació, els ballets, l'striptease o les accions musicals, que va denominar poesia escènica) i en la seva poesia visual, gravats, objectes trobats, escultures, cartells.

"Sonet del pur estrèpit", l'objecte d'aquest treball, prové del volum titulat Sonets de Caruixa, escrit el 1949 i publicat un any més tard per Edicions Cobalt. Va ser el primer poemari de Joan Brossa que va veure la llum de forma impresa, tot i que, en termes de cronologia, va ser precedit per tres que no van arribar a sortir fins algunes dècades més tard. El poema culmina una etapa primerenca en el seu desenvolupament poètic que començà amb poemes hipnagògics lliures, un intent de perpetuar les imatges que el cervell projecta uns segons abans de dormir (un procediment que recordava l'escriptura automàtica surrealista), i que, a proposta de J. V. Foix, que els va qualificar de "veritable avantguarda", Brossa va convertir en sonets regulars amb què va omplir els seus primers quatre poemaris. Prescindint aquí d'una anàlisi detallada de la mètrica dels dos poemes que pretenem confrontar, hem d'assenyalar que una característica principal que els distingeix és, justament, el rigor en les rimes que regeix el sonet i la seva completa absència en el poema de Lorca. El patró formal que obliga el poeta a repetir els fonemes finals - de fet, el "Sonet del pur estrèpit" està constituït sobre la base de dues rimes, la qual cosa reforça la musicalitat i la monotonia del text- li exigeix així mateix limitar el repertori de vocables disponibles en una llengua determinada.

D'acord amb el model clàssic, les respectives estrofes del sonet compleixen una funció determinada dins del poema: els dos quartets defineixen la seva temàtica i la desenvolupen, mentre que els dos tercets aporten una reflexió i la rematen de forma 
sintètica. No obstant això, Brossa, conegut per la seva postura innovadora i iconoclasta, solia oferir solucions sorprenents a les formes i fórmules imposades per la tradició ${ }^{1}$. Vegem ara el desenvolupament del poema i les seves possibles fonts d'inspiració.

La primera estrofa es podria considerar un exemple d'escriptura automàtica, un ressò directe de les tècniques surrealistes i de les seves arrels històriques, que ja hem indicat en el cas de Lorca: Ovidi, Lautréamont, Rimbaud i el seu "arribar al desconegut pel desarreglo de tots els sentits", així com la desconfiança modernista envers la identitat $\mathrm{i}$ integritat del jo. La inspiració rimbaudiana sembla molt probable, ja que l'únic llibre traduït per Brossa va ser el de Rimbaud publicat el 1974 sota el títol Les ungles del guant. Ronda de Rimbaud, que incloía una cinquantena de poemes concebuts com a homenatge al centenari de la Comuna de París. En un breu prefaci, considerant completament prescindible la tasca de presentar el poeta francès, Brossa deia: “¿Per què, doncs, repetir que alzinar significa bosc plantat d'alzines? El fet important és que terres, persones, rius i muntanyes tornin a prendre sentit i moviment" (1974, p. 7). Significativament, el reiterat moviment d'elements del món visible s'associa aquí clarament amb el sentit.

A l'hora d'interpretar el primer quartet com una referència intertextual al poema "Muerte", veiem que Brossa reprèn la imatge transformista de Lorca, que també associa l'acte de la metamorfosi amb un esforç i ruptura d'obstacles ("lluita"). Al mateix temps, des del primer moment, problematitza la dimensió animal de la seqüència lorquiana "cavall-gos-oreneta-abella-cavall" i la seva condició de cercle tancat i repetitiu. A la manera d'una visió més totalitzadora i animista, la relació d'elements que emergeixen un de l'altre trenca qualsevol sèrie d'espècies que podríem associar amb algun ordre: vent-flor-papalló-peix-jo-arrel de la creació. Un fenomen atmosfèric, el moviment de partícules d'aire, es converteix lliurement en una planta i aquesta en un insecte (el que els uneix potser són els colors), després en un animal aquàtic que pretén convertir-se en el jo poètic, el qual, d'altra banda, desitja ser "l'Arrel de la Creació". Aquest últim concepte podria indicar la presència de Déu, però coneixent el profund ateisme de l'autor, més aviat es tracta de qualsevol altra font de l'univers i de les seves formes en continu moviment. La paraula "Creació", escrita amb majúscula, també pot fer referència a l'acte artístic mateix.

El segon quartet, en lloc de desenvolupar la idea anterior de metamorfosi, sembla causar més confusió: l'atmosfera es torna més greu ("sembla fosca", "Vivim en la foscor"); l'autor introdueix un seguit de negacions que més aviat enfosqueixen el significat de l'estrofa: "sentida no té so; / Pot no existir, no obstant, existeix". Una interessant clau interpretativa d'aquest fragment va ser llançada per Pere Gimferrer en el seu llibre sobre Antoni Tàpies (1974, p. 43), on, tot comparant la seva pintura amb la poesia de Brossa, esmenta el "Sonet" i suggereix que un dels punts de referència

${ }^{1}$ Per a més informació sobre experiments formals als quals Brossa sotmet el sonet, vegeu Kurek (2007). 
per al text podria ser la teoria evolucionista de Darwin. El paràgraf final de L'origen de les espècies diu:

Hay grandeza en esta concepción de que la vida, con sus diferentes fuerzas, ha sido alentada por el Creador en un corto número de formas o en una sola, y que, mientras este planeta ha ido girando según la constante ley de la gravitación, se han desarrollado y se están desarrollando, a partir de un principio tan sencillo, infinidad de formas las más bellas y portentosas. (Darwin, 1921, p. 138)

A la llum de la citació anterior, la segona estrofa inscriu les metamorfosis inicials en un context més general; les transformacions més insòlites troben la seva explicació per mitjà d'un dels conceptes científics més reveladors: formen part d'una imatge potent del planeta que gira constantment ("La terra es mou en justa processó"), en la foscor i el silenci, mentre la vida continua d'acord amb les seves lleis, simples i misterioses alhora.

En els dos tercets finals Brossa introdueix una nova perspectiva que sembla més a prop de les fonts d'inspiració que van donar lloc al text analitzat. El poeta recordava que, en el llibre Sonets de Caruixa de què prové el poema, va registrar a manera d'exercici d'habilitat tot un seguit d'estats d'ànim i de lectures: "hi ha sonets que són el dia i altres la nit, els uns són la pluja, els altres el sol, el yin i el yang. El llibre acaba amb un sonet influït pel zen, que jo llegia aleshores" (Coca, 1992, p. 42).

Aquest fragment del poema comença amb una sèrie d'imatges que podríem tractar de metàfores o associar-les amb l'estètica surrealista, que tendeix a confrontar elements contradictoris a fi de qüestionar les bases de la percepció: el món que sembla ser punta d'agulla, espai privat d'altures i profunditats que desorienta ("no pots distingir re"), un bri més gran que una muntanya. No obstant això, la imatge final de la lluna plena reflectida en l'aigua ens guia cap a l'associació desitjada probablement pel poeta: es tracta de tot un repertori d'imatges del budisme zen que, d'una banda, s'oposa a la postura racionalista i la seva aprehensió de les coses i, de l'altra, postula anul·lar la dualitat entre subjecte i objecte, cosa que qüestiona la pròpia noció del "jo". Com explicava D. T. Suzuki, a través de les frases i figures irracionals els mestres zen pretenien obrir l'ésser humà al caràcter real de les coses per tal de satisfer les seves necessitats espirituals. Per tant, com que la llengua no es correspon amb el món -en altres paraules: que el significant s'aparta del referent-, cal abandonar-la a favor dels propis objectes:

Esta destrucción de la tiranía del nombre y la lógica es, al mismo tiempo, emancipación espiritual; pues el alma ya no se halla dividida contra sí. Al adquirir la libertad intelectual, el alma está en plena posesión de sí; el nacimiento y la muerte ya no la atormentan; pues tales dualidades no existen en parte alguna; incluso vivimos a través de la muerte. (Suzuki, 2006, p. 75-76) 


\section{A TALL DE CONCLUSIÓ}

Amb l'enfocament zen suggerit a la fi del poema, "Sonet del pur estrèpit" adquireix coherència estètica i ideològica. Les sorprenents metamorfosis presentades al principi, que en la seva dimensió textual poden estar inspirades en les paraules inicials del poema lorquià i que posteriorment s'associen a l'evolucionisme científic, condueixen en definitiva a la idea d'una unitat còsmica i ontològica en la qual no hi ha oposició ni dependència entre el jo i el món, una unitat que fon tots els elements existents en una font comuna.

Els dos textos comparteixen clarament el motiu de la transformació com a regla principal de l'ésser, extreta de la poesia dels surrealistes espanyols d'abans de la Guerra Civil, en el cas de Lorca interpretat com a efecte de lectures i relectures de Les metamorfosis d'Ovidi, obra força present en la llarga tradició literària d'Espanya. D'aquesta manera, la transformació i el transformisme, com a conceptes principals per al desenvolupament artístic de Brossa, permeten vincular-lo al cànon literari llatí i a les fonts d'inspiració del surrealisme històric, el punt de referència clau per a la neoavantguarda catalana representada pel grup Dau al Set. Tot i que en ambdós autors la imatge de la metamorfosi serveix per il·lustrar diferents visions del món -la mort que posa fi a l'esforç de la transformació, el zen que fon la identitat de cada subjecte que pretén ser un altre en una unitat universal-, el procés mateix de transfiguració, efecte de l'esforç i la lluita, expressa en un pla superior el dubte modern sobre la identitat $i$ intel-ligibilitat de l'univers.

Per a tots dos autors, com per a gran part de l'avantguarda de principis del segle XX (a partir del conegut poema "Zona" d'Apollinaire), el jo del subjecte ha quedat dissolt i liquidat, o si més no ha perdut la seva estabilitat. Ha estat un pas més de la famosa afirmació que expressava la identitat vacil·lant de Gérard de Nerval, escrita sota el seu retrat fotogràfic: "je suis l'autre". Ha estat un pas endavant més respecte a la coneguda frase expressada el 1871 per un Arthur Rimbaud adolescent a la carta al seu mestre de l'escola: "Car JE est un autre". Rimbaud deia: "Car Je est un autre. Si le cuivre s'éveille clairon, il n'y a rien de sa faute" (1972, p. 250). I una mica abans: "C'est faux de dire: Je pense. On devrait dire: On me pense" (1972, p. 249). El conegut "on me pense" rimbaudià demostra que el poeta francès ha reconegut la naturalesa de la identitat moderna, de la qual en constitueixen l'eix el fenomen del desdoblament, l'aillament i la convicció que som alhora éssers autònoms i constructes d'una mirada aliena. 


\section{REFERÈNCIES BIBLIOGRÀFIQUES}

Abril, Ch. (comis.) (1998). Brossa... piensa en Federico. Esculturas y poemas visuales de Joan Brossa. Huerta de San Vicente. Casa-Museo Federico García Lorca. Recuperat de http://www.huertadesanvicente.com/act_ficha.php?id=63.

Alegre Heitzmann, A. (1990-1991). Joan Brossa: azar y esencia de la poesía. Rosa Cúbica. Revista de Poesía, 5, 13.

Bordons, G. (1988). Introducció a la poesia de Joan Brossa. Barcelona: Edicions 62.

Brossa, J. (1974). Les ungles del guant. Ronda de Rimbaud. Barcelona: Curial.

Brossa, J. (1997). La clau a la boca. Barcelona: Barcanova.

del Canto Nieto, J. R. (2007). Las metamorfosis como género literario en la antigüedad clásica y en los relatos de Kafka. EPOS, 23, 21-38. DOI: 10.5944/epos.23.2007.10541

Coca, J. (1992). Joan Brossa. Oblidar i caminar. Barcelona: Edicions de la Magrana.

Darwin, C. (1921). El origen de las especies por medio de la selección natural (trad. de A. de Zulueta). Madrid: Calpe.

Foucault, M. (1999). Estética, Ética y Hermenéutica. Obras esenciales, III (trad. de A. Gabilondo). Barcelona: Paidós.

Fuentes Vázquez, M. (1992-1993). La transformación: un recurso expresivo en Poeta en Nueva York, de Federico García Lorca. Universitas Tarraconensis. Revista de Filología, 14, 135-150.

García Lorca, F. (1997a). Obras completas, I: Poesía. Barcelona: Galaxia Gutenberg \& Círculo de Lectores.

García Lorca, F. (1997b). Obras completas, II: Teatro. Barcelona: Galaxia Gutenberg \& Círculo de Lectores.

García Lorca, F. (2015). Poeta en Nueva York. Barcelona: Galaxia Gutenberg.

Gimferrer, P. (1974). Antoni Tàpies i l'esperit català. Barcelona: Polígrafa.

Koczanowicz, L. (2018). Tożsamość jako niewygoda. Dwie genealogie nowoczesnej hamartii. Teksty Drugie, 2, 335-353.

Koczanowicz, L. (2020). Anxiety and Lucidity. Reflections on Culture in Times of Unrest. Nova York: Routledge. DOI: 10.18318/td.2018.2.21

Kurek, M. (2007). "Un nou vers demana feina". Sonet w poetyckich poszukiwaniach Joana Brossy. Dins T. Eminowicz-Jaśkowska \& A. Sawicka (eds.). Almanach kataloński (Katalonia - Walencja - Baleary-Andorra) (p. 115-130). Cracòvia: Księgarnia Akademicka.

Kurek, M. \& Ziarkowska, J. (2014). “Ellos son el compendio y la breve crónica del tiempo”. Los actores en el metateatro de Federico García Lorca y de Joan Brossa. Dins K. Kumor \& K. Moszczyńska-Dürst (eds.). Del gran teatro del mundo al mundo del teatro. Homenaje a la Profesora Urszula Aszyk (p. 267-277). Varsòvia: Instituto de Estudios Ibéricos e Iberoamericanos.

Lautréamont, C. de (2016). Les Chants de Maldoror. Brusselles: UltraLetters.

Mora, M. (1998, 11 de juny). Brossa recrea "el duende y la alegría" de Lorca. El País. Recuperat de https:/elpais.com/diario/1998/06/11/cultura/897516004_850215.html.

Rimbaud, A. (1972). Euvres complètes (ed. d'Antoine Adam). París: Gallimard.

Suzuki, D. T. (2006). Introducción al budismo zen (trad. de H. V. Morel). Buenos Aires: Kier [Publicat originalment el 1934]. 